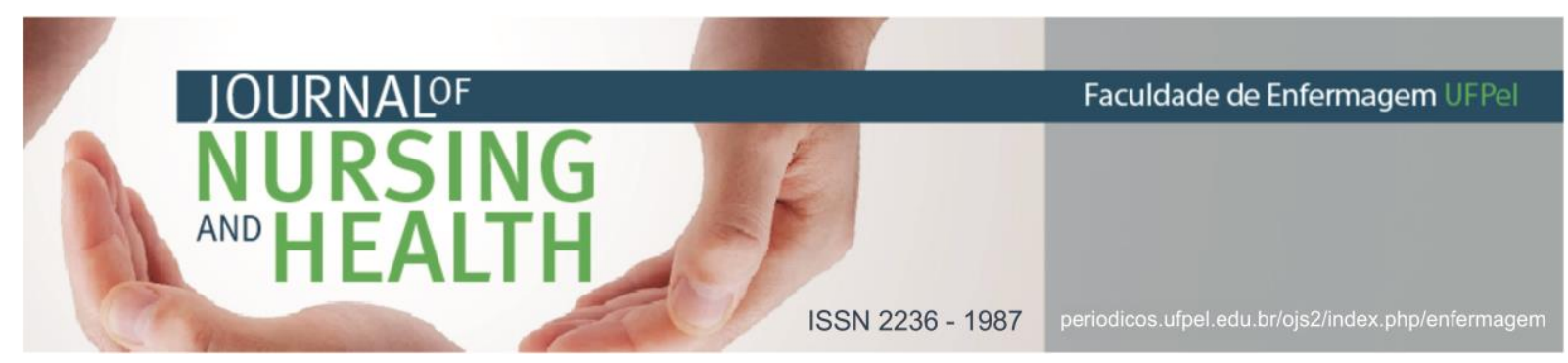

ARTIGO ORIGINAL

\title{
Orientações de profissionais da saúde sobre aleitamento materno: o olhar das puérperas
}

\author{
Health professionals' guidance on breastfeeding: the look of mothers \\ Orientación de profesionales de la salud sobre lactancia materna: el aspecto de las \\ mujeres puerperales
}

Marina Ramos BATISTA ${ }^{1}$, Aline Alves VELEDA², Débora Fernandes COELHO ${ }^{3}$, Fernanda Peixoto CORDOVA $^{4}$

\begin{abstract}
RESUMO
Objetivo: conhecer as percepções das puérperas em relação às orientações de profissionais da saúde sobre aleitamento materno. Métodos: estudo qualitativo de caráter descritivo, desenvolvido de junho a agosto de 2014 em Porto Alegre, RS. Participaram puérperas que haviam realizado a primeira consulta de puericultura. A coleta de dados ocorreu através de entrevistas semiestruturadas e análise dos dados ocorreu através da Análise de Minayo. 0 estudo foi aprovado em comité de ética em pesquisa. Resultados: as orientações sobre aleitamento são percebidas como momentos de ensino entre profissional e mulher, remetendo a um modelo de transmissão de informação, com enfoque tecnicistas e desconsiderando as necessidades individuais. Considerações finais: a maneira como as são realizadas não estão contribuindo efetivamente com a educação em saúde, não possibilitam a participação das mulheres e a contextualização de suas vivências. É preciso trabalhar com a educação participativa, possibilitando a construção conjunta de saberes significativos sobre amamentação. Descritores: Aleitamento materno; Educação em saúde; Saúde materno-infantil; Enfermagem.
\end{abstract}

\begin{abstract}
Objective: this work aims to know the perceptions of puerperal women in what concerns breastfeeding orientation received by professionals. Methods: qualitative descriptive research, conducted from June to August 2014. The participants were puerperal women who had given birth. Data was collected through semi-structured interviews and was analyzed using the Analysis of Minayo. The ethics committee on research approved the study. Results: orientation about breastfeeding was understood as a teaching method between women and professionals, suggesting that information is transmitted. The orientation sessions are usually performed in a technical way, and are focused on health problems rather than the actual women's needs. Conclusion: the way guidelines on breastfeeding are conducted are not effectively contributing to health education, it does not allow the participation of women and the context of their experiences. It is necessary to work with education in participatory health and enable the joint construction of significant knowledge on breastfeeding.
\end{abstract}

Descriptors: Breastfeeding; Health education; Maternal and child health; Nursing.

\footnotetext{
${ }^{1}$ Enfermeira. Residente em Atenção Materno Infantil e Obstetrícia no Grupo Hospitalar Conceição. Porto Alegre, Rio Grande do Sul(RS), Brasil. E-mail: marina.ramos.b@hotmail.com

2 Enfermeira. Doutora em Enfermagem. Docente na Universidade Federal de Ciências da Saúde de Porto Alegre, RS, Brasil. E-mail: alineav@ufcspa.edu.br

${ }^{3}$ Enfermeira. Doutora em Enfermagem. Docente na Universidade Federal de Ciências da Saúde de Porto Alegre, RS, Brasil. E-mail: deborafe@ufcspa.edu.br

${ }^{4}$ Enfermeira. Mestre em Enfermagem. Enfermeira no Hospital de Clínicas de Porto Alegre, RS, Brasil. E-mail: fcordova@hcpa.edu.br
} 


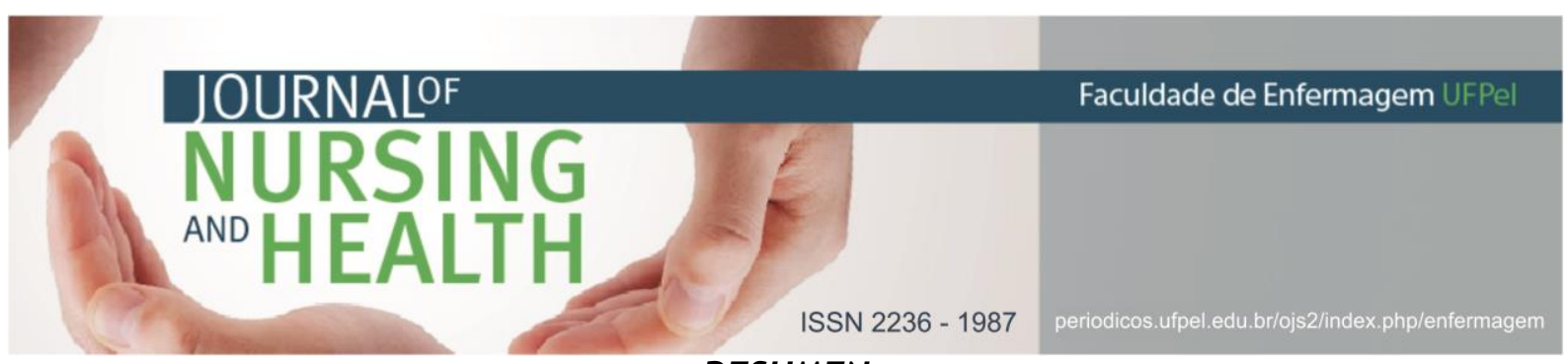

RESUMEN

Objetivo: conocer las percepciones de las puérperas con relación a las orientaciones profesionales sobre el amamantamiento. Método: estudio cualitativo descriptivo, llevado a cabo de junio a agosto de 2014. Participaron de la pesquisa puérperas. Los dados fueron recolectados por medio de entrevistas semiestructuradas y el análisis de datos se dio a través del Análisis de Minayo. El estudio fue aprobado por el comité de ética. Resultados: las mujeres perciben las orientaciones sobre amamantamiento cómo prácticas de enseñanza tradicional, elucidando un modelo de transmisión. Las orientaciones acontecen de manera mecanicista direccionadas a problemas. Consideraciones finales: la forma en que se llevan a cabo las directrices no están contribuyendo de manera efectiva a la educación para la salud, ya que no permite la participación de las mujeres. Hay que trabajar con la educación en la salud participativa y permitir la construcción conjunta de conocimiento significativo sobre sobre el amamantamiento.

Descriptores: Lactancia materna; Educación en salud; Salud materno-infantil; Enfermería.

\section{INTRODUÇÃO}

O aleitamento materno é uma prática de benefícios reconhecidos e amplamente difundida. Recomenda-se o aleitamento materno exclusivo até os seis meses de vida da criança. ${ }^{1}$ Para tanto, considera-se aleitamento materno exclusivo a alimentação da criança apenas com leite humano, seja ele da própria mama materna ou ordenhado. ${ }^{1}$ No Brasil, apesar de um progresso no índice de aleitamento materno, esta prática ainda está longe do ideal, sendo o desmame precoce influenciado por diversos aspectos tais como: apoio fornecido as mulheres, introdução precoce de outros alimentos e orientações fornecidas durante o período gestacional e o puerpério. $^{1-2}$

De acordo com II Pesquisa de Prevalência de Aleitamento Materno nas capitais brasileiras e Distrito Federal, no Brasil a prática do aleitamento exclusivo em crianças menores de seis meses de vida é de $41 \%$, sendo que a média de duração deste é de 54, 1 dias. ${ }^{2}$ Já o aleitamento complementado com outros alimentos, dura em média 341,6 dias. Esses dados permitem perceber a introdução precoce de outros alimentos na dieta das crianças, as quais deixam de ser amamentadas exclusivamente em seio materno durante os primeiros seis meses.

Como forma de aumentar a prática do aleitamento exclusivo, foi criada em 1990 pela Organização Mundial da Saúde (OMS) e Fundo das Nações Unidas para Infância (UNICEF) a Iniciativa Hospital Amigo da Criança. Essa iniciativa pretende modificar práticas profissionais inadequadas com o intuito de "promover, proteger e apoiar o aleitamento materno". Para isso, ela estabelece dez passos para o sucesso do aleitamento que devem ser preconizados dentro das instituições de aderirem à iniciativa. Esses dez passos trazem recomendações que abordam práticas e orientações que incentivem e melhorem a prática da amamentação. ${ }^{3}$

Dentre essas recomendações está a sistematização do alojamento conjunto, um local favorável para o estímulo da prática do aleitamento materno por proporcionar maior interação e comunicação entre mães e bebês. ${ }^{4}$ Nesse ambiente, além dos cuidados biológicos necessários à mulher e ao recém-nascido, existe a 
ISSN 2236 - 1987

puérperas,

necessidade de uma assistência
humanizada, na qual os profissionais incentivem 0 empoderamento das mulheres para tomada de decisão em relação a sua prática de amamentação. ${ }^{5}$

Considerando que o incentivo ao aleitamento materno deve ocorrer de forma contínua, do pré-natal ao puerpério, e que nos primeiros dias após o parto a mulher apresenta-se fragilizada devido à transição ao papel materno, o enfermeiro tem um papel bastante significativo na atenção básica. Neste cenário, este profissional pode auxiliar, orientar, acolher e apoiar a mulher que está amamentando, considerando o seu contexto social em cada momento deste cuidado. ${ }^{6-7}$ Este cuidado pode ser desenvolvido tanto na atenção prénatal e nos momentos de puericultura, no âmbito da atenção básica, quanto nos espaços de assistência ao trabalho de parto e parto, em alojamentos conjuntos e centros obstétricos.

Tendo em vista a importância e relevância da temática sobre aleitamento materno, a construção deste trabalho de pesquisa deu-se a partir de vivências da pesquisadora, nas quais foi possível observar dúvidas e dificuldades das puérperas frente ao aleitamento materno e aos primeiros cuidados com o recém-nascido. Também, observou-se que as práticas profissionais em relação a essas dúvidas são bastante objetivas, resumindo-se em orientações sucintas, sem despender tempo e atenção à mulher e ao recém-nascido. Desta forma, surgiram inquietações em relação aos conteúdos, formas e aplicabilidade das orientações de aleitamento materno realizadas às desenvolvimento deste estudo.

Afinal, tanto em materiais oficiais, quanto em materiais institucionais diversos, percebemos que a prática do aleitamento materno relaciona-se muito fortemente com orientações sobre técnicas, posicionamento, indicações, contraindicações, vantagens e desvantagens da amamentação exclusiva e propriedades nutricionais do leite materno, desconsiderando muitas vezes o contexto vivido pelas mulheres e principalmente os fatores socioculturais que a cercam. No entanto, são estes fatores que podem determinar a amamentação exclusiva até os seis meses de vida, são as experiências vividas pelas mulheres e suas famílias, as práticas prévias e os conhecimentos populares que podem determinar as escolhas sobre a amamentação que a mulher irá fazer, sendo aspectos muitas vezes desconsiderados nos momentos de educação em saúde. E é justamente este o ponto de lacuna que conduziu ao desenvolvimento deste estudo.

Partindo de todas estas concepções, este estudo teve como questão norteadora: quais as percepções das puérperas acerca das orientações de profissionais da saúde sobre aleitamento materno? O objetivo deste trabalho foi conhecer as percepções das puérperas em relação às orientações de profissionais da saúde sobre aleitamento materno. Acredita-se que este estudo contribui para qualificar a assistência à mulher durante sua gestação, parto e pósparto com ênfase nos aspectos relacionados ao aleitamento materno $\mathrm{e}$, por consequência, qualificando a 
atenção à criança nos seus primeiros anos de vida e no decorrer de seu desenvolvimento.

\section{MATERIAIS E MÉTODOS}

Trata-se de um estudo qualitativo de caráter descritivo que teve como cenário de pesquisa seis Unidades de Saúde da Família (USF), todas pertencentes ao Distrito Docente Assistencial da Universidade Federal de Ciências da Saúde de Porto Alegre, escolhidas a partir de indicações de enfermeiras atuantes nesta região, totalizando seis devido a saturação dos dados. A população participante desse estudo foram mulheres, puérperas, cujos partos foram realizados em um Hospital Amigo da Criança e que já haviam realizado a primeira consulta de puericultura na sua unidade de saúde de referência. Os critérios de inclusão nesse estudo foram: ter dezoito anos ou mais; estar no puerpério tardio (do $10^{\circ}$ ao $45^{\circ}$ dia pós parto); ter permanecido com o recémnascido no Alojamento Conjunto de um Hospital Amigo da Criança; já ter realizado a primeira consulta de puericultura na sua unidade de saúde de referência e ter condições de manter diálogo. Foram excluídas do estudo mulheres cujos recém-nascidos permaneceram internados em Unidade de Terapia Intensiva Neonatal por qualquer período de tempo; aquelas cujos recém-nascidos possuíam alguma má formação congênita; mulheres que permaneceram internadas em Unidade de Terapia Intensiva após o parto por qualquer período de tempo e aquelas com contraindicação absoluta à amamentação.

A coleta dos dados ocorreu no período de junho a agosto de 2014. As mulheres foram indicadas pelos enfermeiros das USF, considerando que estes tinham conhecimento sobre o hospital em que as mulheres foram atendidas no momento do nascimento de seus bebês e dos demais dados necessários para preencher os critérios de inclusão. Posteriormente, com o auxílio dos agentes comunitários de saúde, as mulheres foram convidadas a participar da pesquisa e entrevistadas em visita domiciliar.

A entrevista foi semiestruturada com roteiro norteador, com uma duração de mais ou menos uma hora e tendo quatro questões norteadoras: "Você foi orientada sobre a amamentação por profissionais da saúde? Em quais momentos?"; "Quais orientações você lembra de ter recebido?"; "O que você achou das orientações que recebeu?" e "Você utilizou as orientações que recebeu?". Cabe salientar que foram consideradas todas as abordagens sobre aleitamento realizada por profissionais de saúde diversos durante o pré-natal, parto e puerpério, em todas as esferas da assistência: da atenção básica ao nível hospitalar.

0 término da coleta deu-se pelo critério de saturação dos dados, que consiste no momento em que o pesquisador entende que já conseguiu compreender a lógica do grupo estudado. ${ }^{8} \mathrm{~A}$ análise dos dados ocorreu através da Análise Temática. ${ }^{8}$ Inicialmente, as entrevistas foram transcritas e lidas, ressaltando falas que atendessem aos objetivos do estudo e, posteriormente, categorizadas, permitindo a análise e interpretação, correlacionando com a literatura científica. 


\section{JOURNALOF \\ NURSING \\ AND HEALTH}

ISSN 2236 - 1987

realizadas, durante todos os meses e a cada encontro individual ou coletivo, por meio das consultas, grupos e materiais instrucionais, utilizados com acolhimento e respeitando os saberes da mulher e sua família. Nesta pesquisa, as participantes realizaram seis consultas ou mais, o número indicado pelo Ministério da Saúde para um pré-natal ser considerado adequado, mas fica o questionamento de como as informações sobre amamentação estão sendo trabalhadas nestes espaços formais de cuidado.

A partir das entrevistas semiestruturadas, as falas das mulheres foram dividas em duas categoriais. A primeira categoria aborda aspectos relacionados ao modelo de educação em saúde que traz o profissional como educador e a mulher como aprendiz do processo de amamentação, reforçando o modelo biomédico de cuidado, orientando de maneira mecanicista. $\mathrm{Na}$ segunda categoria, são abordadas falas das mulheres relacionadas ao apoio ou a falta dele durante as orientações sobre aleitamento materno.

\section{Categoria ensinaram": 1:"Eles me orientações tecnicistas e modelo biomédico de cuidado}

Nesta categoria, encontra-se na fala das participantes o modelo tradicional de educação, o qual é centrado na transferência de conhecimentos e considera o educador como detentor dos saberes que serão passados ao aprendiz. No contexto da amamentação esse conhecimento transmitido resume-se a questões tecnicistas, deixando de abranger aspectos importantes da vivência e da 


\section{JOURNALOF \\ NURSING \\ AND}

ISSN 2236 - 1987

informações que permitam a reflexão e a decisão, assim como a empatia entre a mulher e 0 profissional. ${ }^{10}$ Contudo, considerando que a amamentação vai além da questão biológica, abrangendo 0 aspecto social, cultural e psicoemocional, a comunicação entre profissional e cliente é essencial neste contexto. ${ }^{11}$

No estudo ao se referirem aos agentes de cuidado, as mulheres se referem às profissionais enfermeiras e sua participação nas orientações. 0 profissional enfermeiro como parte da equipe, deve participar do cuidado no período puerperal, auxiliando a mulher nas adaptações ao papel materno para que este seja alcançado de forma integral e envolva os aspectos pessoais, a família, questões sociais, culturais e profissionais. ${ }^{6}$

Outra percepção encontrada na fala das mulheres é que as orientações oferecidas pelos profissionais baseiamse na técnica do aleitamento materno, orientando o posicionamento e a pega, principalmente.

o médico do posto, ele me ensinou assim a posição, o jeito de deixar ele e tal. Que não era pra ficar assim, que era pra ficar mais direitinho. $E$ no hospital também, a mesma coisa assim, e sobre ele pegar todo... aqui, a auréola (E6).

Esse daqui, de pegar, de botar ela bem próximo ao corpo, não segurar assim, segurar assim, pra não trancar o leite. Foi só, não foi muita coisa não (E6).

Eles me ensinaram que ele tinha que abocanhar bem todo mamilo (E5). 


\section{JOURNALOF \\ NURSING \\ ANO HEALTH}

Ela mandava, eu ia e voltava [da unidade de saúde], ia e voltava, mas ela fez só umas perguntas básicas, só (E2).

Muitas vezes as orientações sobre aleitamento materno refletem 0 modelo biomédico e mecanicista, com técnicas e posições adequadas e esperadas, deixando de contemplar aspectos culturais e sociais relacionados à amamentação. Os profissionais limitam-se a ações de ordem biológica e atividades de rotina. ${ }^{12,13}$ No Caderno de Atenção Básica que traz a temática de aleitamento materno e nutrição complementar, a técnica relacionada à amamentação é abordada intensamente, entretanto, o texto reforça que não basta ao profissional conhecimentos básicos e técnicos sobre o tema, é necessário saber aconselhar a mulher, valorizando-a, acolhendo-a e empoderando-a. ${ }^{1}$

Ainda, ao referirem-se as orientações sobre aleitamento recebidas, muitas mulheres evidenciaram recebê-las nos momentos de dificuldades, sendo apoiadas apenas quando apresentaram alguma intercorrência relacionada ao ato de amamentar.

Ah foi quando elas viram que eu não estava tendo leite, daí veio uma assistente social e uma nutricionista lá. Daí foi quando elas me ensinaram (E4).

Ela me explicou também, porque no caso o peito estava machucado, daí ela viu. Daí ela disse até pra eu colocar casca de banana pra melhorar (E3).
Olha, depois que eu ganhei ela, ela não mamou. Mas como empedrou, eles estavam sempre fazendo massagem, me ensinaram a fazer massagem também. Foi só nesse momento (E6).

No início da amamentação é essencial que os profissionais incentivem e apoiem a puérpera no estabelecimento desta prática, sendo importante identificar precocemente possíveis problemas. ${ }^{13}$ Entretanto fazse necessário promover o aleitamento materno de forma precoce e integral, juntamente com as outras orientações durante o pré-natal e puerpério, com o intuito de auxiliar as mulheres no enfrentamento de dificuldades que possam surgir durante a amamentação. ${ }^{14-16}$ Nesse sentido, é importante valorizar a mulher em todos os seus aspectos, transcendendo questões biológicas e não apenas focando na amamentação como importante para saúde infantil, devese perceber a mulher de maneira integral, dando atenção às questões sociais e culturais durante a gestação e puerpério. ${ }^{13}$ Desta forma, são necessárias modificações na maneira de abordagem as mulheres, conhecendo as necessidades maternas e enfocando no seu modo de vida. ${ }^{11}$

Categoria 2: "Ela disse que estava tudo bem": o apoio como componente essencial ao cuidado

Nesta categoria, foram encontrados na fala das mulheres aspectos relacionados a ter ou não apoio durante 0 processo da amamentação. Foi possível evidenciar falas que expressam a falta de apoio, ressaltando sua importância, assim 


\section{IOURNAIOF \\ NURSING \\ ANo HEALTH}

como falas que demonstram a importância do apoio de forma integral.

São evidentes os momentos de falta de apoio e a importância deste. Muitas mulheres demonstraram dificuldades em lidar com os momentos que vão além da técnica, mas sim, abrangem as emoções relacionadas ao puerpério e ao processo de aleitamento materno.

Nas primeiras vezes ali no hospital eu me bati. Em vez de elas dizerem como é que era. Eu tentava lembrar como é que eu via as pessoas dando (E1).

Eu sei que é muito importante o leite materno e eu queria muito dar o leite materno. Só que ele chorou desesperadamente, não tinha (E4).

Eu fiquei meio desesperada, que ele chorava, chorava, chorava e não saía (E4).

Essas falas vêm ao encontro dos resultados de outro estudo, que evidenciou a falta de apoio na amamentação, da equipe ou familiares, e sua influência negativa para o estabelecimento de dificuldades ou desejo de não amamentar. Percebese que as tecnologias não invasivas de cuidado, como o apoio, não são utilizadas nas orientações de amamentação, algo que precisa ser modificado. ${ }^{17}$

Muitas vezes também, o suporte oferecido pelos serviços de saúde é inadequado, isso devido ao pouco tempo e quantidade insuficiente de funcionários. ${ }^{18-19}$ Algo que também é percebido na seguinte fala:
ISSN 2236 - 1987

Talvez ela não... as outras estavam cansadas porque elas trabalham bastante (E5).

0 suporte às mulheres para o aleitamento materno necessita de profissionais comprometidos e sensíveis ao cuidado, mas também depende de uma estrutura de serviços que garanta ao profissional tempo para desenvolver orientações que garantam uma abordagem dos aspectos relevantes para a mulher e seu contexto de vida. É preciso que os serviços e as instituições compreendam a importância do dimensionamento adequado das equipes que atendem mulheres, famílias e recém-nascidos, haja vista que o tempo para a educação em saúde é diferenciado e exige qualificação, organização e sensibilidade.

Segundo autores, muitas mulheres evidenciam a necessidade de apoio, de forma que este ressalte os aspectos socioculturais e psicológicos que estão envolvidos no aleitamento. ${ }^{19}$ É importante que os profissionais auxiliem a mulher de forma humanizada, influenciando positivamente na prática da amamentação. ${ }^{6}$

A responsabilização das mulheres também foi evidente nas falas das participantes. Algumas demonstraram em suas falas sentirem-se responsáveis pelo entendimento das orientações recebidas, assim como o sentimento de responsabilidade e de obrigação em amamentar, independente de seus desejos e sentimentos.

Mas daí no caso eles tinham dado uma palestra, mas fui eu que saí porque parecia que ele estava chorando... mas eles deram uma 


\section{HOURNATOF \\ NURSING \\ AND HEALTH \\ palestra sim, eu que não fiquei} (E3).

Não tem que gostar, entendeu... é o certo, pra mim é o certo (E2).

0 aleitamento materno é visto como um dever da mulher, sendo sobreposto ao seu desejo de querer ou não amamentar. Este resultado vem ao encontro de um estudo, que observou que $o$ ato de amamentar é percebido como obrigação da mãe. ${ }^{14}$ Mesmo a mulher não podendo permanecer no momento formal de informação sobre aleitamento materno, a mesma sentiuse a responsável pelo não aprendizado, já que foi oferecido, mas ela "não ficou' para "aprender". Muitas mulheres são julgadas e consideradas culpadas por não desejarem amamentar ou por dificuldades que levem ao insucesso da amamentação, mantendo 0 aleitamento por obrigação. ${ }^{17}$ É preciso problematizar a forma como lidamos com a amamentação e as práticas discursivas utilizadas em torno de uma "maternidade natural", discurso que agencia processos de ordem história, social e cultural que podem interferir na vida das mulheres e produzir certos modos de ser mulher-mãe. ${ }^{19}$

Faz-se necessário ressaltar uma única entrevista em que surgiram falas da participante demonstrando a importância de receber apoio de algum profissional da saúde. Fica evidente que o suporte de forma acolhedora, em que o profissional demonstra interesse pela mulher, faz-se essencial e é um diferencial percebido pela mulher.

Ela veio, teve a maior paciência, veio e me ensinou direitinho (E5).
ISSN 2236 - 1987

Para a mulher, reservar um tempo para observar a amamentação, oferecendo auxílio de maneira prática e interessando-se por ela e por suas necessidades é entendido como um apoio adequado ao aleitamento materno. Ainda, faz-se importante trazer afirmações encorajadoras durante o ato de amamentar, algo que fica evidente na fala da participante E5. ${ }^{18}$

As outras vieram ver, a primeira me ensinou, mas eu não entendi. Na hora eu botei e não consegui botar. Depois, veio outra, também não entendi direito, elas falavam rápido assim. Daí veio a última, veio, ficou o maior tempo ali comigo. Quando ela viu que ele pegou direitinho, ela falou pra mim: agora ele está mamando (E5).

Ainda, faz-se importante ressaltar que a continuidade de atendimento com um mesmo profissional auxilia no estabelecimento de vínculo e confiança. Assim, ter um contato prévio com a mulher facilita o estabelecimento de um vínculo entre a puérpera e o profissional. Nesse sentido, os sistemas de saúde que oferecem um cuidado continuado facilitam a criação deste vínculo. ${ }^{18}$

Por fim, ressalta-se que, entre todas as perspectivas e saberes levantados nas falas das participantes, fica a importância de pensar e realizar formas de "saber-fazer" educação em saúde, maneiras que garantam o aprendizado colaborativo, libertador e principalmente significativo para as mulheres. É preciso uma aprendizagem que garanta o exercício contínuo da curiosidade, da valorização dos saberes pessoais, da inquietude sobre 
o tema e sobre o que envolve os sujeitos envolvidos e seus contextos sociais.

É necessário discutir com os sujeitos sobre sua realidade concreta, associando-se os aprendizados com a vida, com sua experiência social e sua intimidade. Portanto, para trabalhar com educação em saúde no contexto do aleitamento materno, pensando-se em impacto sobre os índices brasileiros de morbimortalidade infantil, não basta apenas palestras, informações pontuais, folders explicativos ou ensino de técnicas, é preciso que este saber seja construído socialmente com as mulheres, a partir de suas histórias com a amamentação e do quanto, como ser autônomo e transformador, elas podem resignificar o aleitamento materno como prática individual de suas vidas. ${ }^{20}$

\section{CONSIDERAÇÕES FINAIS}

Com este estudo foi possível perceber que a assistência à mulher em relação ao aleitamento materno é realizada da maneira parcial. As orientações seguem conceitos tradicionais de educação em saúde, constituindo-se de ensinamentos, passados dos profissionais para as mulheres de maneira tecnicista e rotineira. É necessário que os profissionais entendam a educação em saúde como um compartilhamento de conhecimento, para que possam realizar uma assistência adequada e para que as mulheres conheçam uma forma de atendimento diferenciada em relação à prática atual, buscando seus direitos por atendimentos mais humanizados e resolutivos.

As mulheres reconhecem a necessidade de serem apoiadas para
ISSN 2236 - 1987

amamentar, destacando profissionais que atuam de maneira diferenciada dos demais, apoiando de forma paciente e individualizada. Observase, portanto, que a assistência ao aleitamento materno carece de profissionais que enxerguem cada mulher em seu contexto, saibam acolher e tenham uma escuta qualificada para atender suas necessidades, fortalecendo sua confiança e segurança para o estabelecimento do aleitamento materno.

Considerando os resultados encontrados, observa-se que as orientações de técnica da amamentação não estão sendo realizadas plenamente. Considerando que as práticas de aleitamento ainda não são ideais, permite-se concluir que possivelmente não sejam de orientações tecnicistas que as mulheres necessitem, mas sim de alguém que as escute, sanando suas dúvidas e compartilhando saberes a partir de um vínculo pré-estabelecido entre profissional e puérpera. Faz-se necessário manter os investimentos voltados às políticas de saúde que deem ênfase ao atendimento humanizado e acolhedor, integrando os profissionais cada vez mais nessas práticas. É importante ressaltar, que para que os profissionais consigam realizar este cuidado de excelência, é necessário que seus locais e equipes de trabalho estejam adequados, permitindo que os profissionais despendam um maior tempo para assistência sem comprometer a saúde profissional e qualidade do atendimento.

Nesse sentido, a Enfermagem, uma profissão que trabalha com o 
cuidado em saúde, deve estar atenta para as necessidades das mulheres nestes momentos, deixando de realizar suas práticas de forma mecânica. É necessário que os profissionais enxerguem a mulher integralmente, não apenas como um seio que amamenta e, para tanto, sugere-se que os profissionais busquem conhecer as histórias e contextos das mulheres, realizando orientações sobre aleitamento materno condizentes com suas realidades, apoiando-as principalmente no início da amamentação, acompanhando-as e mostrando-se disponíveis para encorajá-las, auxiliando no estabelecimento da autoconfiança e vínculo durante a amamentação. Para - alcance das mudanças nas orientações sobre aleitamento materno, recomenda-se que sejam utilizadas outras práticas de educação em saúde, não tão inovadoras, mas ao mesmo tempo ainda não tão utilizadas nos contextos assistenciais, tais como os grupos de puerpério e a consultoria em aleitamento materno. Sugere-se a realização de outros estudos que abordem diferentes práticas de educação em saúde sobre a temática do aleitamento materno, com o intuito de qualificar a assistência materno infantil.

Faz-se importante ressaltar que, ao questionar-se sobre as orientações recebidas sobre aleitamento materno junto às mulheres, incluiu-se tanto as orientações fornecidas durante o prénatal, quanto aquelas recebidas no hospital e na consulta de puericultura. No entanto, as mulheres referiram-se, quase sempre, às orientações recebidas no nível hospitalar de atenção, logo após o parto e nas primeiras vinte e quatro horas após o nascimento. Isso possibilitou o questionamento das pesquisadoras sobre como vem sendo desenvolvida a educação para o aleitamento materno durante a gestação? E será que a mesma vem sendo desenvolvida durante o pré-natal? Como está acontecendo a abordagem dos profissionais sobre esse tema?

Afinal, não pareceu que as mulheres percebiam que haviam recebido orientações durante o prénatal ou por não se lembrarem de receberem ou por não terem recebido realmente, o que nos preocupou já que consideravelmente 0 momento das consultas de pré-natal seria o mais adequado para a reflexão e orientação sobre aleitamento materno. A abordagem da amamentação deve ser um continuum na assistência, iniciando durante a gestação e permanecendo durante o puerpério, sempre contextualizada e abordando aspectos que vão além da técnica e da suposta "forma correta" de amamentar.

Como limitações deste estudo destaca-se a não escuta dos profissionais de saúde dos diversos setores de cuidado materno-infantil, o que complementaria as percepções das mulheres atendidas e possibilitaria um olhar mais amplo sobre a questão pesquisada. No entanto, este não era o objetivo neste momento, servindo como base para pesquisas futuras. Indicamos, para maior visibilidade do tema, novas pesquisas com objetivo de investigar como está ocorrendo a orientação sobre aleitamento materno com as mulheres - gestantes e/ou puérperas-, principalmente durante 0 pré-natal, com enfoque na análise de materiais instrucionais utilizados e nos discursos e formas de abordagem 


\section{NURSING \\ AND \\ HEALTH}

utilizadas pelos profissionais, em especial os enfermeiros.

Por fim, enfatiza-se a importância da compreensão da educação em saúde como ferramenta de aproximação entre usuários dos serviços e profissionais de saúde, tornando os momentos de assistência em constantes espaços de discussão, reflexão e aprendizado compartilhado. É preciso um conjunto de sensibilidade e ciência para trabalhar com aleitamento materno e não apenas uma abordagem tecnicista, dura e estritamente biomédica, a qual evidentemente não está dando conta do tema. Afinal, amamentar, antes de tudo é um ato cultural e não puramente biológico o que exige de todos os profissionais um comprometimento com uma educação em saúde contextualizada, engajada, política e que respeite as experiências e os saberes vividos.

\section{REFERÊNCIAS}

1. Ministério da Saúde (BR). Departamento de atenção básica. Saúde da Criança: aleitamento materno e alimentação complementar. Brasília; 2015.

2. Ministério da Saúde (BR). Pesquisa Nacional de Demografia e Saúde da Criança e da Mulher, PNDS 2006: dimensões do processo reprodutivo e da saúde da criança. Brasília; 2009.

3. Ministério da Saúde (BR). Iniciativa Hospital Amigo da Criança: revista atualizada e ampliada para o cuidado integrado. Módulo 4: avaliação e monitoramento do hospital. Brasília; 2010.

4. Beck AMO, Assunção KO, Barbosa LR, Gomes E. Influência do ambiente
ISSN 2236 - 1987

hospitalar nos aspectos relacionados ao aleitamento materno. Rev soc bras fonoaudiol. $2012 \mathrm{dez}$;17(4):464-8.

5. Maroja MCS, Silva ATMC, Carvalho AT. Iniciativa Hospital Amigo da Criança: uma análise a partir das concepções de profissionais quanto às suas práticas. Rev port saúde publica. 2014 jan/jun;32(1):3-9.

6. Catafesta F, Zagonel IPS, Martins M, Venturi KK. A amamentação na transição puerperal: o desvelamento pelo método de pesquisa-cuidado. Esc Anna Nery. 2009 jul/set;13(3):609-16.

7. Queiroz PH, Antonieta KS, Nozawa MR. Enfermeiras da atenção básica na promoção do aleitamento materno. Rev pesqui cuid fundam [Internet]. 2009 ago/dez[acesso em 2014 jun 28];(2):1879-88. Disponível em: http://www.seer.unirio.br/index.php /cuidadofundamental/article/view/14 06/pdf_388

8. Minayo MCS. 0 desafio do conhecimento: pesquisa qualitativa em saúde. 14. ed. São Paulo: Hucitec; 2010.

9. Ministério da Saúde (BR). Conselho Nacional de Saúde. Resolução 466 de 12 de dezembro de 2012: diretrizes e normas regulamentadoras sobre pesquisa envolvendo seres humanos. Brasília; 2012.

10. Santos RV, Penna CMM. A educação em saúde como estratégia para o cuidado à gestante, puérpera e ao recém-nascido. Texto contexto enferm. 2009 out/dez;18(4):652-60.

11. Teixeira MM, Vasconcelos VM, Silva DMA, Martins EMCS, Martins MC, Frota MA. Percepções de primíparas sobre orientações no pré-natal acerca do 


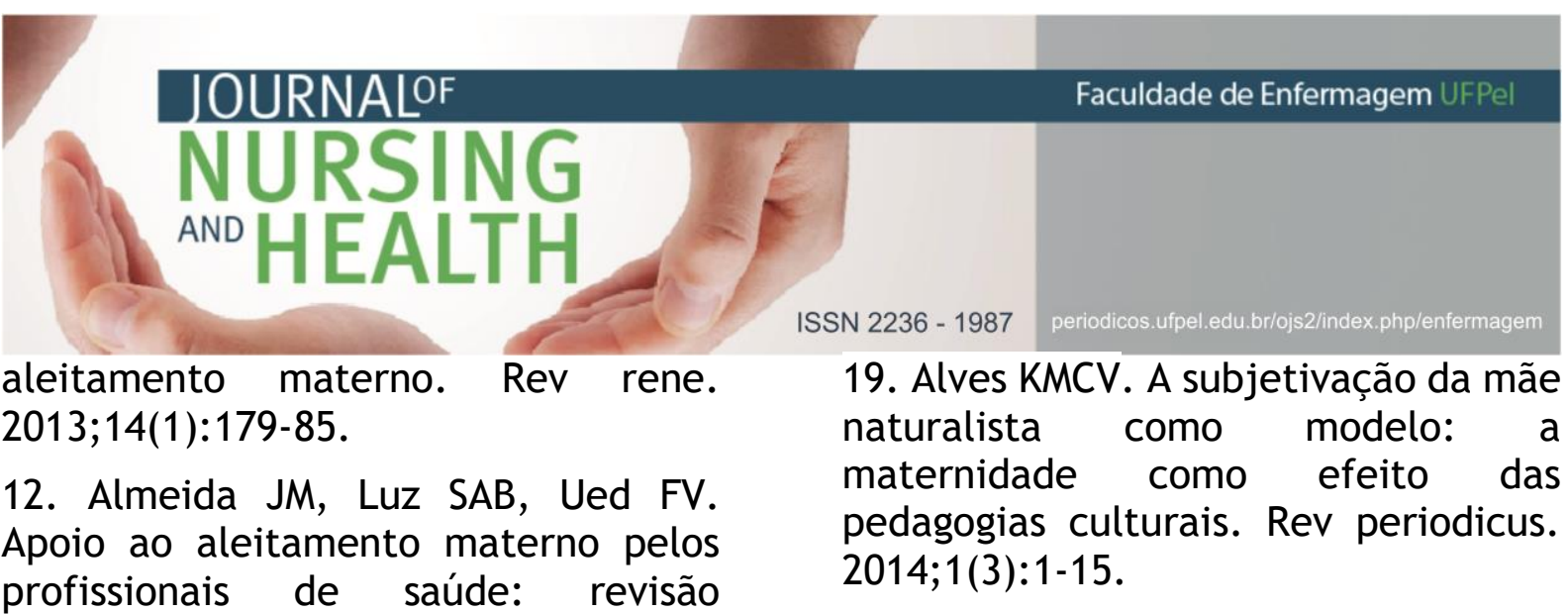
integrativa de literatura. Rev paul pediatr. 2015;33(3):355-62.

13. Marques ES, Cotta RMM, Franceschini SCC, Botelho MIV, Araujo RMA, Junqueira TS. Práticas e percepções acerca do aleitamento materno: consensos e dissensos no cotidiano de cuidado numa Unidade de Saúde da Família. Physis (Rio J). 2009;19(2):439-55.

14. Rodrigues AP, Padoin SMM, Guido LA, Lopes LFD. Fatores do pré-natal e puerpério que interferem na autoeficácia em amamentação. Esc Anna Nery. 2014 abr/jun;18(2):257-61.

15. Silva NM, Waterkemper R, Silva EF, Cordova FP, Bonilha ALL. Conhecimento de puérperas sobre amamentação exclusiva. Rev bras enferm. 2014 mar/abr;67(2):290-5.

16. Souza MD Filho, Gonçalves PNT Neto, Martins MCC. Avaliação dos problemas relacionados ao aleitamento materno a partir do olhar da enfermagem. Cogitare enferm. $2011 \mathrm{jan} / \mathrm{mar} ; 16(1): 70-5$.

17. Meirelles LX. Amamentação sob ótica do desejo e das tecnologias não invasivas de cuidado de enfermagem: narrativas de vida [dissertação]. Rio de Janeiro (RJ): Universidade do Estado do Rio de Janeiro; 2014.

18. Schmied V, Beake $S$, Sheehan A, McCourt C, Dykes F. Women's perceptions and experiences of breastfeeding support: a metasynthesis. Birth. 2011 mar;38(1):49-58. 